\title{
O FINANCIAMENTO DA EDUCAÇÃO NO MERCOSUL: A REALIDADE DO BRASIL E DO URUGUAI
}

\author{
FINANCIAMIENTO DE LA EDUCACIÓN EN MERCOSUR: LA REALIDAD DE \\ BRASIL Y URUGUAY
}

\section{FINANCING EDUCATION IN MERCOSUR: THE REALITY OF BRAZIL AND URUGUAY}

\author{
Kellcia Rezende SOUZA ${ }^{1}$ \\ Daniely Honorato da SILVA ${ }^{2}$ \\ Vanessa Alcântara Cardoso MENDES ${ }^{3}$
}

RESUMO: O trabalho analisa a proteção normativa do financiamento à educação básica no Brasil e Uruguai, países membros do Mercado Comum do Sul (Mercosul). Assim, foi realizada, mediante abordagem qualitativa, uma pesquisa bibliográfica e documental (Constituições e Legislações educacionais vigentes). A escolha pelos dois países se deve pela distinção nas suas formas de organização político-administrativas de Estado, o que permite identificar as similitudes e diferenças de um Estado Federal (Brasil) e um Estado Unitário (Uruguai). Evidenciamos que não há uma harmonização normativa dos dois países no tocante ao financiamento educacional. Constatamos, também, que só o Brasil assegura a vinculação de um percentual mínimo do orçamento em sua constituição. Por outro lado, na legislação uruguaia, a competência referente ao financiamento educacional está vinculada ao governo central. As reflexões suscitadas colocaram em evidência avanços e limites no âmbito normativo referente ao financiamento educacional dos países investigados, cuja realidade carece de desenvolvimento de pesquisas.

PALAVRAS-CHAVE: Educação básica. Financiamento. Internacionalização da educação. Mercosul.

RESUMEN: El trabajo analiza la protección normativa del financiamiento de la educación básica en Brasil y Uruguay, países miembros del Mercado Común del Sur (Mercosur). Así, mediante un enfoque cualitativo, se llevó a cabo una investigación bibliográfica y documental (Constituciones y legislación educativa vigente). La elección para los dos países se debe a la distinción en sus formas de organización político-administrativa del Estado, lo que permite identificar las similitudes y diferencias de un Estado Federal (Brasil) y un Estado Unitario

\footnotetext{
${ }^{1}$ Universidade Federal da Grande Dourados (UFGD), Dourados - MS - Brasil. Professora Adjunta da Faculdade de Educação. Doutorado em Educação Escolar (UNESP). ORCID: https://orcid.org/0000-0002-8663-4615. Email:kellcia@hotmail.com

${ }^{2}$ Universidade Federal da Grande Dourados (UFGD), Dourados - MS - Brasil. Graduando em Pedagogia da Faculdade de Educação (UFGD). Bolsista de Iniciação Científica do Conselho Nacional de Desenvolvimento Científico e Tecnológico (CNPq). ORCID: https://orcid.org/0000-0003-4311-8415. E-mail: honoratodaniely@gmail.com

${ }^{3}$ Universidade Federal da Grande Dourados (UFGD), Dourados - MS - Brasil. Professora Substituta na Faculdade de Educação dos Cursos de Graduação. Mestre em Teoria e Pesquisa do Comportamento (UFPA). ORCID: https://orcid.org/0000-0003-4745-6446. E-mail: alcantaracardoso@gmail.com
} 
(Uruguay). Mostramos que no existe una armonización normativa entre los dos países en materia de financiamiento educativo. También encontramos que solo Brasil asegura que un porcentaje mínimo del presupuesto esté vinculado a su constitución. Por otro lado, en la legislación uruguaya, la competencia en materia de financiamiento educativo está vinculada al gobierno central. Las reflexiones planteadas destacaron avances y límites en el ámbito normativo en cuanto al financiamiento educativo de los países investigados, cuya realidad carece del desarrollo de la investigación.

PALABRAS CLAVE: Educación básica. Financiación. Internacionalización de la educación. Mercosur.

ABSTRACT: The work analyzes the normative protection of the financing of basic education in Brazil and Uruguay, member countries of the Southern Common Market (Mercosur). Thus, through a qualitative approach, a bibliographic and documentary research was carried out (Constitutions and current educational legislation). The choice for the two countries is due to the distinction in their forms of political-administrative organization of the State, which allows identifying the similarities and differences of a Federal State (Brazil) and a Unitary State (Uruguay). We show that there is no normative harmonization between the two countries regarding educational financing. We also find that only Brazil ensures that a minimum percentage of the budget is linked to its constitution. On the other hand, in Uruguayan legislation, competition in educational financing is linked to the central government. The reflections raised highlighted advances and limits in the regulatory environment regarding educational financing in the countries investigated, whose reality lacks the development of research.

KEYWORDS: Basic education. Financing. Internationalization of education. Mercosur.

\section{Introdução}

A cooperação internacional entre os países a partir de interesses em comum, almeja alcançar objetivos de forma pactuada. Para tanto, definem um sistema institucionalizado de tomada de decisões e estabelecem normas internacionais que regulamentam as respectivas ações por meio da constituição de blocos regionais. Nesse viés, o Mercado Comum do Sul (Mercosul) foi criado com o intuito de assegurar essas prerrogativas no contexto da América do Sul.

O Mercosul foi criado pelo Tratado de Assunção em 1991, com o objetivo de promover a livre circulação de bens, serviços e capitais entre os países do Cone Sul Argentina, Brasil, Paraguai e Uruguai, por meio da eliminação dos direitos alfandegários e restrições não tarifárias de mercadorias. Trata-se de um pacto regional para o fortalecimento econômico dos respectivos países. Em 2012, a Venezuela ingressou como quinto país membro do bloco. No ano de 2017, em razão do descumprimento de compromissos 
democráticos assumidos pelos países do Mercosul, a Venezuela foi suspensa de forma temporária (SOUZA, 2017).

Segundo Souza, Kerbauy e Silva (2020), ainda que o Mercosul seja um acordo que abarca, eminentemente, o setor econômico e comercial, tem incorporado, desde o seu início, outros setores que possuem estrita relação com o desenvolvimento político, econômico, cultural e social dos Estados que o integram, dentre eles, a educação. A pauta educacional no âmbito do Mercosul, foi incorporada a partir da criação do Setor Educacional do Mercosul. Trata-se de um espaço institucional de coordenação das políticas educacionais dos países membros, mediante a regulamentação dos Planos de Ação, que são instrumentos que objetivam garantir, pelas definições de estratégias e metas, um espaço educacional integrado.

A pauta educacional no Mercosul é discutida em um espaço institucional específico, que é o Setor Educacional do Mercosul. Nessa vertente, é relevante compreendermos como é regulamentado o financiamento da educação no Brasil e no Uruguai, que são países membros do bloco. Mesmo que o Mercosul tenha cinco países membros, optou-se pela seleção de Brasil e Uruguai, pois trata-se de dois países que dispõem de organização políticaadministrativa do Estado de forma diferenciada. Essa realidade, devido ao tempo limitado para a realização do estudo, permite que sejam interprestadas as semelhanças e as diferenças de um país federal e outro unitário.

Nessa perspectiva, o objetivo do trabalho consiste em analisar a normatização do financiamento da educação básica no Brasil e Uruguai, países membros do Mercosul. Para tanto, recorreu-se a pesquisa bibliográfica e documental com o enfoque qualitativo. A fonte documental foi constituída pelas Constituições Federais e pelas principais legislações vigentes que regem a educação básica (Leis de diretrizes bases educacionais e/ou leis equivalentes), tendo como categoria de análise as diretrizes de financiamento de ensino da educação básica presentes nesses documentos. Os dados coletados na pesquisa documental foram confrontados com as reflexões suscitadas pela literatura da área, procurando comparar e colocar em evidência avanços e limites do financiamento da educação entre dois países que compõe o Mercosul.

\section{O Mercosul e a organização político-administrativa de Brasil e Uruguai}

Transcender os objetivos comerciais dos mercados dos países da América do Sul consiste em um dos desafios que se fez presente na trajetória do Mercosul. Assim, é parte fundamental de um processo aprofundado de integração regional não só o desenvolvimento 
econômico, como também o social. Nesse sentido, canalizar esforços para a coordenação de políticas reservadas a áreas como saúde, cultura e educação, são vitais para o avanço integracional do bloco.

Os contornos de um projeto regional de integração educacional na América do Sul iniciam-se com a própria origem do Mercosul, como evidenciado no Tratado de Assunção, que, em seu preâmbulo, ressalta a importância do desenvolvimento econômico associado à justiça social. Esse reconhecimento sinaliza que o avanço da economia deve estar em consonância com as melhorias das condições de vida dos povos dos Países-membros do bloco, ou seja, o avanço econômico não deve estar dissociado das melhorias sociais, em que a educação se configura como uma das bases.

\begin{abstract}
Mas, embora a educação não tenha vínculo direto com a agenda comercial, neste início de discussões (1991), a diplomacia ministerial, em consonância com o arcabouço institucional do MERCOSUL, a enfatizou de acordo com seus possíveis vínculos com o projeto vigente do Mercado Comum e, diretamente, com suas estratégias econômicas. Com esta visão, a reflexão acerca do papel da educação para a consecução da integração econômica começava a tornar-se um tema passível de preocupações (GOIN, 2008, p. $83)$.
\end{abstract}

A pauta educacional no âmbito do Mercosul foi incorporada a partir da criação do Setor Educacional do Mercosul. No entender de Souza (2017) trata-se de um espaço institucional de coordenação das políticas educacionais dos países membros, mediante a regulamentação dos Planos de Ação, instrumentos que objetivam garantir, pelas definições de estratégias e metas, um espaço educacional integrado.

Aos longo das quase três décadas de Mercosul, foram regulamentados pelo Setor Educacional do bloco seis planos de ação, a saber, o primeiro (1992-1994), que foi prorrogado até junho de 1998; o segundo (1998-2000); o terceiro plano (2001-2005); o quarto plano (2006-2010); o quinto (2011-2015) e o sexto plano (2016-2020).

Observamos que, ao longo dos planos, especificamente nos dois últimos, é central que a consolidação da integração regional educacional esteja relacionada à garantia da educação enquanto um bem dos cidadãos mercosulinos. Trata-se de implementar políticas que propiciem o acesso irrestrito e com qualidade ao conhecimento, com atenção especial, sobretudo, aos grupos marginalizados. Contudo, denota-se que os principais desafios para a educação básica estão relacionados ao acesso, retenção escolar, repetência, deserção, melhoria da qualidade da aprendizagem e o financiamento educacional (SOUZA, 2017). 
Segundo a autora, a possibilidade de integração educacional dependerá da quantidade de acordos que se logra firmar, como também da consolidação das estruturas institucionais. Para tanto, o reconhecimento das necessidades educacionais dos sistemas e das diferenças existentes entre os países corrobora com a conformação do desenvolvimento de um mercado regional articulado às melhorias das condições sociais da sua população.

Dentre as diferenças existentes entre os dois países, destaca-se as formas de organização política-administrativas dos seus respectivos Estados que, por sua vez, influenciam diretamente a implementação das políticas públicas e, consequentemente, a gestão do seus respectivos financiamentos. O Uruguai é Estado Unitário, ao passo que Brasil é Estado Federado. Segundo Arretche (2002), a distinção entre Estados Federativos e Unitários está nos modos de distribuição da autoridade político-administrativa, ou seja, o grau de centralização e descentralização da organização do Estado.

Os que são organizados por entes federados são dividido verticalmente, de tal modo que distintos níveis de governo têm autoridade sobre a mesma população e território. Nesses Estados, o governo central e os governos locais são independentes entre si e soberanos em suas respectivas jurisdições, pois cada governo local, cuja jurisdição pode variar, conforme assim o definir a Constituição está resguardado pelo princípio da soberania, o que significa que estes são atores políticos autônomos com capacidade para implementar (pelo menos, algumas das) suas próprias políticas. Nos Estados unitários, apenas o governo central tem autoridade política própria, derivada do voto popular direto. A unidade do Estado nacional está garantida pela concentração de autoridade política, fiscal e militar no governo central, ao passo que a autoridade política dos governos locais é derivada de uma delegação de autoridade da autoridade política central. Em tese, portanto, a autonomia dos governos locais é mais reduzida nos Estados unitários do que nos federativos (ARRETCHE, 2002, p. 28).

Essas especificidades nas formas de Estado entre os países do Mercosul traz desdobramentos na elaboração do ordenamento jurídico. Conforme Arretche (2002), nos Estados Unitários, os departamentos distritais não possuem autonomia para definir leis e/ou dispor de uma forma própria de organização dos serviços públicos. A legislação, nesse caso, é regulamentada pelo governo central, que tem a incumbência de garantir os meios para a sua plena implantação. Logo, a responsabilidade jurídica é centralizada. Já nas federações, cuja organização administrativa e política é descentralizada, há a divisão de competências entre o governo federal e os governos dos demais entes federados.

Um dos aspectos que está diretamente relacionado às responsabilidades das administrações dos governos são as garantias orçamentárias, pautadas no planejamento da destinação de recursos para os serviços públicos, bem como na projeção do desenvolvimento 
econômico e social. Assim sendo, mensurar a organização política-administrativa e a variação da capacidade financeira de um país serão determinantes não só para entender o desempenho de sua economia, como, também, para a implantação das políticas públicas (SOUZA, 2017).

\section{Financiamento da educação básica no Brasil e no Uruguai}

A educação deve estar assegurada em um amplo marco jurídico, pois o usufruto desse direito representa a criação de condições individuais e coletivas para o desenvolvimento da consciência sobre a realidade em que se vive e sobre as relações existentes nos contextos dos quais os sujeitos são históricos, sociais, culturais, econômicos e políticos (CURY, 2007). Nesse sentido, o financiamento é o principal indicador do esforço de um país para garantir e, sobretudo, efetivar o direito educacional.

A ampliação de investimentos públicos para a educação, em valores reais, tende a potencializar o desenvolvimento econômico e, principalmente, social de uma nação. Por outro lado, a manutenção ou redução pode desencadear uma mudança de prioridades por parte do país, que trará impactos à efetiva concretização do direito à educação (SOUZA; KERBAUY; SILVA, 2020).

A concretização da educação como um bem social, obrigatório e gratuito, garantido constitucionalmente, demandará custeio. Assim, o aporte necessário para a manutenção das instituições de ensino, remuneração e valorização dos profissionais da educação e construção de novas estruturas físicas, ou seja, para subsidiar as políticas educacionais, advêm da própria sociedade, mediante o pagamento de impostos que serão redistribuídos pelo Estado. Os investimentos educacionais devem estar previstos no orçamento ${ }^{4}$ a partir das receitas de um país e devem ser classificados de acordo com as normatizações. Porém, o percentual de transferência para a área demandará a normatização de um aparato legal (OLIVEIRA; MORAES; DOURADO, 2009).

O Brasil institui, em sua constituinte, a regulamentação do financiamento educacional. A Carta Magna brasileira, no que concerne à organização e divisão de responsabilidades no

4 “O orçamento é uma fase do planejamento, ou seja, ele é uma lei que orienta a execução dos planos governamentais. Na Lei Orçamentária, devem estar previstas todas as receitas e todas as despesas públicas correspondentes a um ano. Assim, no orçamento, seja da união, do estado, do Distrito Federal ou do município, devem estar previstas todas as fontes de receitas destinadas, por exemplo, à educação (impostos, transferências, salário-educação e outras) e todas as despesas que serão realizadas, compreendendo os gastos com pessoal, material, serviços, obras, equipamentos e outros. Receita é o conjunto dos rendimentos de um estado, de uma entidade ou de uma pessoa, destinados a enfrentar os gastos necessários. A receita pública é composta por receitas correntes e receitas de capital. A receita de impostos consiste na soma de tributos que o Estado exige de pessoas físicas e jurídicas, coercitivamente, sem lhes oferecer uma contraprestação direta e determinada" (OLIVEIRA; MORAES; DOURADO, 2009, p. 2-3). 
provimento financeiro da educação entre os entes federados, estabelece, no artigo 211, que a União, os estados, o Distrito Federal e os municípios organizarão seus sistemas de ensino em regime de colaboração. Esse artigo também define que os municípios atuarão no Ensino fundamental e na Educação Infantil; Estados e o Distrito Federal serão responsáveis, prioritariamente, pelo Ensino Fundamental e Médio; e a União organizará o sistema federal de ensino e dos territórios (BRASIL, 1988).

A organização do financiamento no sistema educacional do Brasil, conforme a Constituição Federal, é caracterizada pela divisão de competências e responsabilidades entre União, estados, Distrito Federal e municípios dos diferentes níveis, etapas e modalidades educacionais. Essa determinação, que define prioridades do ensino, não veda ou restringe a atuação dos entes federados em outros níveis e etapas da educação brasileira, mas é considerada como um parâmetro para a gestão dos recursos orçamentários (BABINSKI, 2010).

A estrutura legal do financiamento do país é baseada nas competências atribuídas aos seus entes federados: União, Estados, Distrito Federal e Municípios. Cabe à União aplicar seu orçamento na rede federal de ensino e, também, na transferência de recursos para compor as receitas dos Estados e Municípios. Nesse viés, a normatização do financiamento no país é pautada pelo regime de colaboração (ABRAHÃO, 2005).

O artigo 212 destaca que a União aplicará, anualmente, nunca menos de 18\%, e os Estados, o Distrito Federal e os Municípios, 25\%, no mínimo, da receita resultante de impostos, compreendida aquela proveniente de transferências, na manutenção e desenvolvimento do ensino. Babinski (2010) destaca que é importante fazer a ressalva de que as constituintes estaduais e as leis orgânicas dos municípios poderão estabelecer percentuais maiores de aplicação dos recursos para a educação.

Os recursos para o financiamento educacional no Brasil são oriundos das arrecadações de impostos da sociedade, o que representa que a parcela expressiva das fontes da União, estados, Distrito Federal e Municípios é proveniente do recolhimento tributário. Abrahão (2005) considera que, ao vincular legalmente um percentual para os gastos com a educação mediante o fluxo de receitas, o país assegura uma importante ferramenta jurídica para garantir a concreta disponibilidade de recursos para o cumprimento da responsabilidade do poder público na garantia do direito à educação.

Cada governante, quando chega ao poder, não pode usar o dinheiro público como bem entender. Para garantir a educação de todas e todos, a Constituição Federal estabelece um mínimo de gastos anuais que União, 
estados, Distrito Federal e municípios devem destinar às políticas de educação. São as chamadas despesas obrigatórias com o ensino (RIZZI, GONZALEZ; XIMENES, 2011, p. 43).

O inciso $3^{\circ}$ institui que a distribuição dos recursos públicos assegurará a prioridade do atendimento às necessidades do ensino obrigatório, no que se refere à universalização, garantia de padrão de qualidade e equidade, nos termos do plano nacional de educação (BRASIL, 1988).

É notório o fato de o texto constitucional salientar que os recursos deverão ser empenhados, prioritariamente, ao ensino obrigatório, vislumbrando a sua universalidade com equidade e qualidade. Além da vinculação de impostos, a Constituição brasileira prevê as seguintes fontes de financiamento da educação: contribuições (salário-educação, renda de loteria, contribuições sobre o lucro e seguridade social); desvinculação de receitas da União; e operações de crédito. Embora se observem diversificadas fontes, a vinculação de impostos ainda constitui a principal fonte de receitas no financiamento da educação obrigatória pública, tanto por parte da União quanto dos estados, Distrito Federal e municípios (SOUZA, 2017).

As reservas constitucionais do financiamento vinculadas à gratuidade no ensino oficial e o universalismo do direito à educação básica e seu caráter obrigatório para as pessoas de quatro a 17 anos, para Cury (2007), não só contêm um horizonte equalizador, como também são viabilizadores das políticas educacionais no país, e que, historicamente, estiveram sempre tendentes a um conservadorismo social.

O artigo 213 expõe que os recursos públicos serão destinados às escolas públicas, podendo ser dirigidos a escolas comunitárias, confessionais ou filantrópicas, definidas em Lei. Além desses dois artigos, a constituinte apresenta, nos incisos do artigo 206, a valorização dos profissionais da educação, questão que está relacionada ao financiamento educacional (BRASIL, 1988).

A valorização dos profissionais da educação, assegurada na Carta Magna brasileira, decorreu da regulamentação da Emenda Constitucional n. 53/2006. Esse instrumento jurídico também institui a criação do Fundo de Manutenção e Desenvolvimento da Educação Básica e de Valorização dos Profissionais da Educação (FUNDEB), que é de natureza contábil e com previsão de duração de 14 anos. O objetivo do fundo consiste em garantir o financiamento do desenvolvimento e da manutenção da educação, bem como a melhoria da valorização dos profissionais envolvidos na educação por todos os entes federados.

O Fundeb determina, pois, a distribuição proporcional dos recursos aos Estados e Municípios conforme o número de alunos matriculados nas respectivas redes públicas de 
educação básica. Sena (2008) esclarece que, um dos avanços expressivos do FUNDEB, que substituiu o Fundo de Manutenção e Desenvolvimento do Ensino Fundamental e de Valorização do Magistério (FUNDEF), reside, principalmente, na sua abrangência, que contempla, como um mecanismo de financiamento, todas as etapas da educação básica, diferentemente do fundo anterior, que delimitava apenas o Ensino Fundamental enquanto única etapa para a destinação do fundo.

No entender de Souza (2017), a Constituição Federal Brasileira de 1988 e suas consequentes emendas não só ampliaram o gasto educacional, mas expandiram a estrutura institucional de competências e responsabilidade compartilhada pela educação obrigatória brasileira entre os entes federados. Todavia, é importante ressaltar que essa expansão não traduz necessariamente a exclusividade dos entes em financiar as ações educacionais. Mesmo com a institucionalização do regime de colaboração, o financiamento educacional depende significativamente do aporte de recursos da união, sobretudo se consideramos as assimetrias de arrecadação entre os estados e municípios brasileiros.

Já a LDB brasileira dispõe de uma sessão específica sobre o financiamento da educação, cujo texto retoma vários pontos estabelecidos na Constituição, conforme se segue: Art. 68. Serão recursos públicos destinados à educação os originários de: I - receita de impostos próprios da União, dos estados, do Distrito Federal e dos municípios; II - receita de transferências constitucionais e outras transferências; III - receita do salário-educação e de outras contribuições sociais; IV - receita de incentivos fiscais; V - outros recursos previstos em lei (BRASIL, 1996).

Evidencia-se que tanto a Constituição quanto a LDB/1996 definem a previsão de outras fontes de captação de recursos que podem ser destinados à educação, tais como: contribuições sociais, receitas de incentivos fiscais, receita do salário-educação e outras contribuições previstas em lei. Considerando que o financiamento da educação interfere diretamente na garantia do acesso e da gratuidade da educação como um direito, Oliveira, Moraes e Dourado (2009) destacam que, além de definir a educação como um direito e estabelecer a responsabilidade de cada ente federado (União, estados e municípios) na garantia da oferta da educação básica, a Constituição Federal de 1988 (art. 212) vincula um percentual de recursos específicos que cada ente tem que empenhar na manutenção e desenvolvimento da educação.

Embora a legislação brasileira, sobretudo a Constituição Federal, confira maior proteção jurídica ao orçamento educacional, é preciso registrar que, ao final do ano de 2016, o congresso do país aprovou a Emenda Constitucional n. 95/2016, que alterou o Ato das 
Disposições Transitórias para instituir o Novo Regime Fiscal. Essa normatização instituiu o Novo Regime Fiscal no âmbito dos Orçamentos públicos e da Seguridade Social da União, que passará a vigorar pelos próximos vinte exercícios financeiros (BRASIL, 2016).

A referida Emenda Constitucional designa que os recursos destinados à educação pela União entre o período de 2018 a 2036 serão equivalentes aos 18\% das receitas de impostos, tendo como referência os apurados em 2017, que só poderão ser alterados anualmente, de acordo com a inflação acumulada conforme o Índice Nacional de Preços ao Consumidor Amplo (IPCA). Isso significa que, independente do aumento das receitas de impostos do país, não serão ampliados os recursos para a educação.

Monlevade (2014, p. 66-67), em análise sobre o financiamento da educação no Brasil, esclareceu que a Constituição Federal de 1967 adotou a mesma lógica, ao conservar os percentuais de impostos para a educação dos Estados e Municípios e retirar o dever constitucional da União. $\mathrm{O}$ autor esclarece que essa legislação foi contraditória, pois “[...] exatamente quando o governo federal arrecadou as maiores receitas da história, o aumento de encargos financeiros de todas as esferas administrativas foi viabilizado pelo corte na qualidade da educação pública e nos salários de seus profissionais".

A Constituição Uruguai não regulamenta especificamente quais os investimentos serão reservados à educação, mas salienta, em seu artigo n. 214, que o Orçamento Geral do Estado será definido para o período de governo, ou seja, cinco anos. Portanto, caberá ao executivo, dentro dos primeiros seis meses do seu mandato, encaminhar para a apreciação e aprovação do legislativo, o que resultará na criação da Lei Nacional do Orçamento.

No entender de Abrahão (2005), a educação, situada no âmbito das responsabilidades do Poder Público e componente do núcleo central dos direitos humanos e dos sistemas que visam o bem-estar social, deve absorver quantidade significativa de recursos públicos. Esses recursos, além de serem cruciais no oferecimento de condições materiais para viabilizar a formulação e implementação das políticas que visam o desenvolvimento educacional, dependem de uma proteção normativa ampla. No Uruguai, a não previsão constitucional e a premissa do vínculo orçamentário estar restrito a uma legislação de governo tende a ser um obstáculo ao atendimento das necessidades e demandas da área. É importante também frisar que o país, por ser um Estado unitário, concentra o financiamento educacional no governo central.

No artigo n. 69 da Carta Magna, o incentivo à prestação de serviços educacionais por instituições privadas a partir da exoneração de impostos tanto nacionais, quanto municipais. "Las instituciones de enseñanza privada y las culturales de la misma naturaleza estarán 
exoneradas de impuestos nacionales y municipales, como subvención por sus servicios" (URUGUAI, 1967).

Conforme Babinski (2010), essa garantia constitucional pode ser interpretada como um incentivo à prestação de serviços educacionais pela iniciativa privada. A bonificação pela exoneração de impostos é uma subvenção do Estado pelos serviços das instituições particulares. A legislação, ao permitir que os recursos públicos sejam dirigidos para essas instituições, induz à redução da presença direta do Estado na área social.

Segundo Frigotto e Ciavata (2003), a destinação de recursos para as instituições privadas pode representar, sobretudo, a transferência de responsabilidade pela prestação do bem público que é a educação. O Estado, desse modo, desarticula o patrimônio público e tende a privatizar os serviços públicos, que são direitos sociais do cidadão. $\mathrm{O}$ mercado se apresenta como um regulador exclusivo de direitos.

A Lei Geral da Educação Uruguaia n. 18.437/2009 institui, em seu artigo n. 19, que o Estado proverá os recursos necessários para garantir o direito à educação e cumprimento do que é regulamentado na referida lei. Art. 19 - "El Estado proveerá los recursos necesarios para asegurar el derecho a la educación y el cumplimiento de lo establecido en la presente ley” (URUGUAI, 2009).

Todavia, a referida Lei não específica quais serão os percentuais destinados à educação, apenas regulamenta, no artigo n. 57, que os recursos da Administração Nacional de Educação Pública (ANEP) serão atribuídos pelas Leis do Orçamento Nacional. A legislação mencionada, no que tange ao Uruguai, consiste na Lei n. 18.719/2010 (Período 2010-2014). Essa normativa prevê que os recursos serão alocados na ANEP, para que essa entidade seja a responsável pela redistribuição entre os departamentos, bem como para os diversos níveis e modalidades educacionais do país. Ademais, a legislação não fixa valores concretos, mas apresenta previsões orçamentárias que serão direcionadas paras as áreas sociais ao longo do período de vigência do governo central (cinco anos), dentre elas, a educação (URUGUAI, 2010).

O financiamento da educação no Uruguai não encontra referência normativa na Constituição do país nem em sua principal lei educacional. Ainda que seja regulamentada em uma lei específica que trata do orçamento geral para o governo, ela estará condicionada à temporalidade de uma gestão, o que pode trazer desdobramentos graves no tocante ao processo de desenvolvimento da área e, sobretudo, para a garantia do direito à educação. 


\section{Considerações finais}

Os resultados apontam que nas normativas a disponibilidade de recursos financeiros investidos na educação nos países do Mercosul são decorrentes de tributos. Em especial, por ser um Estado Unitário, o Uruguai depende, principalmente, da arrecadação de impostos concentradas ao nível do governo central. Identificamos, também, que a legislação brasileira vincula um percentual de recursos específicos destinado à educação, geralmente, esse percentual está associada ao Produto Interno Bruto (PIB). Esse previsão não foi evidenciada nas normativas do Uruguai.

A aplicação de recursos públicos em educação como proporção do PIB é um indicador de que o orçamento que será aplicado na educação deverá acompanhar o ritmo de crescimento da economia do país. Contudo, em casos de recessão econômica, isso se traduz na diminuição de investimentos, como pode-se evidenciar na Emenda Constitucional brasileira n. 95/2016. Nota-se, também, que na legislação brasileira por conta da divisão de responsabilidades entre os entes federados há a definição de um percentual orçamentário próprio desses entes. $\mathrm{Na}$ legislação do Uruguai a competência referente ao financiamento educacional está vinculadas ao governo central.

Percebe-se que, em termos de regulamentação do financiamento educacional no Uruguai, as legislações apontam para a ausência de normativas específicas que digam respeito à organização e à forma de distribuição dos recursos destinados à educação. Assim, o financiamento da educação nesse país, no âmbito normativo, carece de uma maior proteção institucional se consideramos a proteção do direito à educação.

Em decorrência da abrangência do tema, procuramos destacar aspectos referentes, principalmente, ao financiamento da educação básica no ordenamento normativo do Brasil e do Uruguai. Com efeito, denota-se que há um extenso campo de investigação que se encontra aberto para se aprofundar e produzir mais conhecimento sobre o tema.

AGRADECIMENTOS: Ao Conselho Nacional de Desenvolvimento Científico e Tecnológico $(\mathrm{CNPq})$ pela concessão de bolsa de iniciação científica a segunda autora.

\section{REFERÊNCIAS}

ABRAHÃO, J. Financiamento e gasto público da educação básica no Brasil e comparações com alguns países da OCDE e América Latina. Educação e Sociedade, Campinas, v. 26, n. 92, p. 841-858, 2005. 
ARRETCHE, M. Relações federativas nas políticas sociais. Educação e Sociedade, Campinas, v. 23, n. 80, p. 25-48, 2002.

BABINSKI, D. B. de O. O direito à educação básica no âmbito do Mercosul: proteção normativa nos planos constitucional, internacional e regional 2010. 182 f. Dissertação (Mestrado em Direito) - Universidade de São Paulo, São Paulo, 2010.

BRASIL. Constituição da República Federativa do Brasil de 1988. Constituição da República Federativa do Brasil. Brasília: Senado, 1988.

BRASIL. Lei n. 9.394, de 20 de dezembro 1996. Estabelece as diretrizes e bases da educação nacional. Diário Oficial União, Brasília, DF, 23 dez. 1996.

BRASIL. Emenda Constitucional n. 95, de 15 de dezembro de 2016. Altera o Ato das Disposições Constitucionais Transitórias, para instituir o Novo Regime Fiscal, e dá outras providências. Diário Oficial da União, Brasília, DF, 15 dez. 2016.

CURY, C. R. J. A gestão democrática na escola e o direito à educação. Revista Brasileira de Política e Administração da Educação, Recife, v. 23, n. 3, p. 483-495, 2007.

FRIGOTO, G.; CIAVATA, E. Educação básica no Brasil na década de 1990: subordinação ativa e consentida à lógica do mercado. Educação e Sociedade, Campinas, v. 24, n. 82, p. 93 132, 2003.

GOIN, M. O processo contraditório da educação no contexto do Mercosul: uma análise a partir dos planos educacionais. 2008. 140 f. Dissertação (Mestrado em Serviço Social) Universidade Federal de Santa Catarina, Florianópolis, 2008.

OLIVEIRA, J. F.; MORAES, K. N. DOURADO, L. F. O financiamento da educação básica: limites e possibilidades. MEC: Escola de Gestores, 2009.

RIZZI, E.; GONZALEZ, M.; XIMENES, S. Direito humano à educação. 2. ed. Curitiba: Plataforma Dhesca Brasil, 2011. (Coleção Manual de Direitos Humanos)

SENA, P. A legislação do FUNDEB. Cadernos de Pesquisa, São Paulo, v. 38, n. 134, p. 319-340, 2008.

SOUZA, K. R. Direito à educação nos países membros do Mercosul: um estudo comparado. 2017, 346 f. Tese (Doutorado em Educação Escolar) - Universidade Estadual Paulista, Araraquara, 2017.

SOUZA, K. R.; KERBAUY, M. T. M. SILVA, R. S. da. O direito à educação escolar como dimensão da cidadania no Mercosul. Revista on line de Política e Gestão Educacional, Araraquara, v. 24, n. esp. 1, p. 737-746, ago. 2020.

URUGUAI. Constituicion de La Republica com las modificaciones plebiscitadas el 26 de noviembro de 1989, el 26 de noviembro de 1994 y el 8 de diciembro de 1996. Montividéu. 1967.

URUGUAI. Ley n. 18.437 del 16 enero 2009. Ley General de Educación. Montividéu, 2009. 
URUGUAI. Ley n. 18.719 del 19 diciembre 2010. Presupuesto Nacional periodo 2010 2014. Montevidéu, 2010.

\section{Como referenciar este artigo}

SOUZA, K. R.; SILVA, D. H.; MENDES, V. A. C. O financiamento da educação no Mercosul: a realidade do Brasil e do Uruguai. Revista on line de Política e Gestão Educacional, Araraquara, v. 24, n. 3, p. 1272-1285, set./dez. 2020. e-ISSN:1519-9029. DOI: https://doi.org/10.22633/rpge.v24i3.14261

Submetido em: 20/05/2020

Revisões requeridas: $15 / 07 / 2020$

Aprovado em: 03/08/2020

Publicado em: 01/09/2020 